\title{
Sportive Communication Board: A Low Cost Strategy to Improve Communication of BC3-Paralympics Boccia Athletes
}

\author{
Ana Paula de Araújo Alves' ${ }^{1}$, Helena Carla Castro ${ }^{1,2 *}$, Leonardo Alves Miceli², \\ Julio Vianna Barbosa ${ }^{1,3^{*}}$ \\ ${ }^{1}$ Post Graduate Program in Diversity and Inclusion (CMPDI), Federal Fluminense University, Niterói, Brazil \\ ${ }^{2}$ Post Graduate Program in Science and Biotechnology (PPBI), Federal Fluminense University, Niterói, Brazil \\ ${ }^{3}$ Laboratoryof Education Environment and Health (IOC/FIOCRUZ), Fundação Oswaldo Cruz, Rio de Janeiro, Brazil \\ Email: ${ }^{* j u b @ i o c . f i o c r u z . b r, ~}{ }^{\star}$ hcastrorangel@yahoo.com.br
}

How to cite this paper: de Araújo Alves, A. P., Castro, H. C., Miceli, L. A., \& Barbosa, J. V. (2018). Sportive Communication Board: A Low Cost Strategy to Improve Communication of BC3-Paralympics Boccia Athletes. Creative Education, 9, 1743-1762. https://doi.org/10.4236/ce.2018.911127

Received: March 26, 2018

Accepted: August 28, 2018

Published: August 31, 2018

Copyright $\odot 2018$ by authors and Scientific Research Publishing Inc. This work is licensed under the Creative Commons Attribution International License (CC BY 4.0).

http://creativecommons.org/licenses/by/4.0/

(c) (i) Open Access

\begin{abstract}
Boccia is a fun and stimulating physical active sport suitable for people with Cerebral Palsy (CP). The Boccia class three (BC3) players include those with four-limbs-motor-dysfunction with or without $\mathrm{CP}$. These players can request a sport assistant that may help them physically during the game but not in their game strategy. In this work we investigated the use of a supplementary communication sportive board constructed specifically to improve the interaction of Paralympic BC3 players with their sport assistants. This case study enrolled a two-year-experience-CP-BC3 athlete with classification of gross motor function at level 5, severe four limbs dysfunction, low strength and coordination, and no verbal/oral language use but small body movements. This study was performed in a sport club during one month of training, twice a week for two-hour sessions. The sportive communication board (SCB) was designed based on Boccia rules and symbols using white and colored papers, scissors and glue. In the first two training sessions, the Paralympic athlete did not use the sportive board, whereas in the other two sessions the board was tested and the performance was compared. A set of questionnaires was applied to the legal tutor and the sport assistants before and after the SCB tests together with the analysis of the recording of a training session. According to our questionnaires data analysis, a significant contribution to the assistant understanding of the athlete game strategy was noticed by the legal tutor and the sport assistants when using the SCB. Improvement on time playing (reduction of $22 \%$ ) and difficulty imposed to the opponent (increase of $33 \%$ ) were the most important data detected during the tests. According to our video-records, the use of the SCB generated positive effects on the athlete overall performance, improving their communication. In fact, after this study,
\end{abstract}


the BC3 player-which was allowed to keep the sportive board-has always required SCB during her training sets, which reinforced our perception of this material applicability and contribution to the player performance. Thus, we suggest that this SCB may be adapted and more explored to the use in other sport activities helping other Paralympic athletes in their performances as well as other sport assistants in their work activities.

\section{Keywords}

Boccia, Cerebral Palsy, Paralympics, Adapted Boccia, Alternative Communication

\section{Introduction}

According to World Health Organization (WHO), Cerebral Palsy (CP) is a non-progressive chronic brain injury that can occur during prenatal, perinatal, or 1 st to 5 th year of life, characterized by motor impairment (Castellano \& Freire, 2014).

The child with CP presents one or several impairments, ranging from motor injury to cognitive, sensory, language and seizure disorders (Lianza, 2007). Zonta and colleagues (Zonta, Ramalho Júnior, \& Santos, 2011) described cognitive implications in CP and also epilepsy with sensitivity, perception, communication, behavior, muscle and joint problems associated with motor disturbances.

According to the literature, CP can be related to several factors (Rotta, 2002), and the most common cause is the insufficient oxygen level in the brain (e.g. hypoxia). CP is characterized by lesions in the cortex and cerebral subcortex, basal nuclei and cerebellum (Lianza, 2007).

The classification of CP is based on clinical symptoms (hypotonic, ataxic, pyramidal extrapyramidal, and mixed spastic) and topographic distribution (hemiparesis, diplegia and tetraparesis) (de Oliveira, Golin, \& Cunha, 2010). Lianza and colleagues (Lianza, 2007) described tetraparesis and spastic quadriplegia among most severe and common CP (9\% to 43\%). The impairment caused by these lesions occurs in the bilateral pyramidal system (Leite \& Prado, 2004), promoting intense dysfunction in the upper limbs and impaired walking ability (da Fonseca, Cordani, \& de Oliveira, 2005).

Spasticity is one of the most frequent sequelae in central nervous system lesions of $\mathrm{CP}$, exhibiting a combination of factors such as resistance to passive movement and hyper-activation of tendon reflexes (Zonta, Ramalho Júnior, \& Santos, 2011). Spasticity can lead to hyperactive reflexes (hyperreflexia) and changes in muscle activity caused by upper body and head position shifts. Clinical and topographic classifications are related to motor impairment and body localization, describing the limited individual mobility and severity impairments (Shepherd, 1995; Silva, Silva, Pontes, Oliveira, \& Deliberato, 2013).

The Gross Motor Function Measure (GMFM) is a with five levels system de- 
veloped for classification of cerebral paralyzed patients, with emphasis on the evaluation of shifts, mobility and sitting (Zonta, Ramalho Júnior, \& Santos, 2011; Silva, Silva, Pontes, Oliveira, \& Deliberato, 2013). GMFM determines which level best represents the child current limitations and abilities, with emphasis on performance at home, school and community environments (Rosenbaum, Livingston, Palisano, Galuppi, \& Russell, 2007).

Several health areas (e.g. neurology, physiotherapy, occupational therapy, and physical education) are requested for treating CP people (Shepherd, 1995). They suffer from alterations in several functional systems resulting from neurological deficits needing rehabilitation training daily to improve and/or maintain their movements (Tsai, Yu, Huang, \& Cheng, 2014).

Rehabilitation programs become repetitive and may reduce participant's motivation. On that perspective Boccia is a fun and stimulating sport that allows CP people to participate, thus improving their life quality by interacting with people, and making new friends in the game (Huang, Pan, Ou, Yu, \& Tsai, 2014). In fact, Boccia is an adapted sport that can be a tool in the rehabilitation process by facilitating CP treatment besides offering social interactions (Tsai, Yu, Huang, \& Cheng, 2014). Due to the game characteristics, CP with a high impairment degree (e.g. motor and speech) can be included in Boccia, which acts as an incentive for integration of disabled people into an adapted physical activity, including those who use wheelchairs and with severe sequelae (Alvis \& Mejía, 2013).

The rules of the adapted Boccia game require all participants to be in wheelchairs (Huang, Pan, Ou, Yu, \& Tsai, 2014) they play in a delimited boundary line area that includes a throwing box (BIS-FED, 2016). The game main objective is score points by positioning red or blue balls as close as possible to the target white ball, also called Jack (Tsai, Yu, Huang, \& Cheng, 2014). The use of adaptations such as a helmet with pointer, ramps, and sport assistants is allowed to help those athletes with significantly compromised motor skills (Morriss \& Wittmannová, 2011).

Boccia presents four player classes $(\mathrm{BC} 1$ to $\mathrm{BC} 4)$ in which athletes are classified by their functional and physical disabilities (Fong, Yam, Chu, Cheung, \& Chan, 2012). The Boccia class three (BC3) includes players with motor dysfunction on four limbs, with or without $\mathrm{CP}$, that may require someone to help on handling the chair and show difficulties on holding and throwing balls. Thus, it is allowed the participation of a sport assistant to help during the game, but this professional have to stand with his/her back to the sports court, to not influence the player strategy (BIS-FED, 2016).

According to some authors, Alternative Communication (AC) and Extended Communication (EC) are tools for helping on communicating with students with special needs (Manzini \& Deliberato, 2006). The aim of these tools is to promote fully communication and participation of this public, especially at the school environment, through techniques and strategies adapted by a set of symbols and resources (Pelosi, 2008). According to Brazilian Institute of Social 
Technology (ITS) (ITS, 2014), AC offers several resources options aiming to facilitate learning and communication of individuals with sensorial and/or cognitive dysfunctions.

Communication boards with graphic symbols or objects are considered low-tech simple schematic systems, whereas computers or personal electronic communicators are known as high-tech systems (Pelosi, 2008). The cost of the last one may compromise the wide use of them with students with special needs, especially in countries with economic restrictions. On that perspective, low cost devices such as "thematic boards", with figures and symbols, affixing the board on their desk may be used with students with involuntary movements (Manzini \& Deliberato, 2006).

Based in this context, our purpose is to construct and analyze a sportive board with thematic and graphic symbols related to Boccia game to be affixed on the wheelchair of a CP-BC3 athlete. In this case study, we evaluated the effects on the communication between the athlete and her sport assistants as well as its influence on the final games result.

\section{Methodology}

\subsection{Selection Process, Ethical Procedures and Approach}

This case study included the participation of a female BC3 athlete with 23 years old, and non-progressive chronic encephalopathy, spastic quadriplegic with dystonic athetosis. This BC3 is a wheelchair user with third-party help for movement that communicates through facial gestures, body expressions, and a school communication board. She trained at SESI for approximately 5 years (2 hours, 3 times a week) with participation in several São Paulo state tournaments.

The inclusion criteria were: 1) BC3 functional classification for modality division, 2) experience of at least 2 years on practicing Boccia, and 3) participation in weekly training, at least 2 hours twice a week.

The sports assistants (20 to 60 years and high school-master degree levels) had training experience of one or more than three years with Paralympic Boccia athletes acting on state, national and international tournaments. Some of them already acted as judge in Boccia game. The legal tutor was 50 years old and has an incomplete high school education. The legal tutor acted as a sports assistant previously but just in training sets.

A descriptive-analytical study with a qualitative approach was carried out by using semi-structured questionnaires with questions related to the athlete and her communication skills. Meanwhile it was performed the recording and quantitative statistical analysis of her training game. The procedures and protocols were approved by the Ethics Committee of the Brazil (CAAE) on Universidade Federal Fluminense (UFF) platform by the number 59611316.9.0000.5243 submitted in 22/08/2016.

Two semi-structured questionnaires (pre and post-tests) (Appendix) were applied to the legal tutor $(n=1)$ as well to the sport assistants $(n=7)$ of the 
CP-BC3 player before and after the test with the sportive board on the training sessions. The questionnaire applied to the tutor was regarding: 1) CP-BC3 player identification and confirmation of clinical diagnosis; 2) functional impairment; 3) education; 4) participation in Boccia game; and 5) the athlete performance before and after the use of the sportive board.

The questionnaires directed to the sports assistants who worked with the athlete were regarding their experience as game assistant and the performance of the athlete during Boccia training with and without the sportive board.

The analysis of the questionnaire followed the technique used by Bardin and colleagues (Bardin, 2006), with three steps: 1) pre-analysis, 2) exploration of the material, and 3) treatment of results, inference and interpretation (Mozzato \& Grzybovski, 2011). Thus, from the transcription of the interviews some topics were selected based on the interviewed subject testimony.

\subsection{Video Recording and Statistical Analysis}

After the project approval by the CAEE and authorization of the director's of Serviço Social da Indústria (SESI) Suzano, the volunteers/participants were selected according to the inclusion criteria. Then we contacted the athletes and explained the purpose and the research procedures. After accepting on participating on the study they signed the Consent Form for authorizing the data and image uses.

The video recording used a Sony HD Handycam digital camera, with cube measuring $1.5 \times 1.5 \times 1.5$ for calibration of the image, along with the program Kinovea (https://www.kinovea.org) (Kinovea Software Version 0.8.15 for Windows, 2016) that provides numerical elements for interpretation of sports videos. The tests were recorded on a sport court with the official size always in the same position and following the video procedures rules. The correct use of the camcorder allowed the full analysis of the player movements and game strategies.

The shooting was performed during a training session composed of 4 quarters (or ends), the first two without using the sportive board and the last two testing it.

Each player could throw the ball 6 times, alternately, on each quarter. Game time was set on six minutes per ball, according to BC3 classification.

The statistical analysis of the filming was performed by calculating the percentage differences of the mean percentage or the total value, obtained through Descriptive Statistics of quantitative data, using the program Bioestat 5.3 (Ayres, Ayres Júnior, Ayres, \& Santos, 2007). In order to compare the data, we analyzed four variables: mean distance from the target ball, playing time, adversary balls out of bounds, and points taken.

\subsection{BC3-Sportive Board Confection, Training and Usage}

The sportive communication board (SCB) was designed after the analysis of the brief interviews with coaches, sport assistants, and family members who sug- 
gested the use of figures, symbols and colors related to Boccia to assure easy identification by all game participants, despite their reading level.

The images used for constructing the SCB symbols are related to Boccia as suggested by the interviewees. They were located in the internet by using Google search for free images. Images were enlarged and printed on cardboard paper with a white background, generating a thick, easy, accessible and low cost material.

The strategy for using SCB was planned based on BC3 Boccia game logistics and rules. Information for sport assistants and the legal tutor about handling the SCB was carried out during the two-hour training session.

Then, the athlete was presented to SCB for identifying and choosing the figures and symbols for composing their personal sportive board. During the assembly, arrangement and location of the symbols were carefully verified to allow easy handling by the athlete. A simulation was first conducted with the athlete by throwing balls in the playing area with the use of SCB to observe the strategies and game intention attendance by the material.

Then the sport assistants, and legal tutor were also introduced to the final personal SCB. Thus, simulated sets using the SCB were conducted with the athlete and their assistant, according to Boccia rules, following the athlete signaling on the SCB symbols.

In the final test the athlete and sport assistants used the SCB in partnership during the whole training set allowing the evaluation of the athlete-assistant relationship and the interpretation of the commands, as well as the performance along the whole game.

\section{Results and Discussion}

Boccia is a sport that allows different adaptations (e.g. helmets with pointer, ramps, and assistants) and the participation of seriously compromised athletes (Morriss \& Wittmannová, 2011). According to Jeronimo and colleagues (Jerônimo, 2006) in the BC3 classification, the high motor difficulty of these athletes requires assistive technologies such as ramps, which allows athletes that are not able to hold and throw balls, to play anyway.

The Boccia also provides to individuals with a high degree of commitment, both in speech and in mobility, to interact in this competitive sport with another players, thus encouraging social integration (Alvis \& Mejía, 2013). According to Huang and colleagues (Huang, Pan, Ou, Yu, \& Tsai, 2014), children with CP can increase life quality by participating on Boccia and making new friends due to the interaction with another children. In this work we developed a low-cost assistive technology (SCB) to help on $\mathrm{BC} 3$ athletes and assistants communication also aiming to improve interaction of the participants of this sport.

For constructing the SCB prototype, we used the standard measures of a school desk commonly used by the athletes in the wheelchair (Figure 1(a)). Therefore, our SCB is easy to be installed on the player wheelchair desk at training time or to 
be removed after the game. It included two arrows (position of the ramp-right or left), spherical shapes in red and blue color (balls) and rectangle geometric shapes in three different sizes (ramps sizes). The colors of the arrows and ramps were selected based on athlete suggestion of primary colors (red, green and blue) (Figure 1(b)). After construction, we registered SCB project in Brazilian National Library (code number $=016280 \_1 / 6$ ).

According to some authors, the practice of sports is not usual to disable people, especially for cerebral paralyzed patients due to the families' overprotection or restrictions. The benefits of socialization, identification, and/or development of their sport abilities are enhanced when they perform adapted physical activities (Alves \& Cruz, 2014). Cardoso and colleagues (Cardoso, 2011) reinforced that the benefits of playful or competitive sports are clear as they act as positive tools in the process of rehabilitation. These activities optimize not only physical but also psychological and social conditions of these people. Thus, the

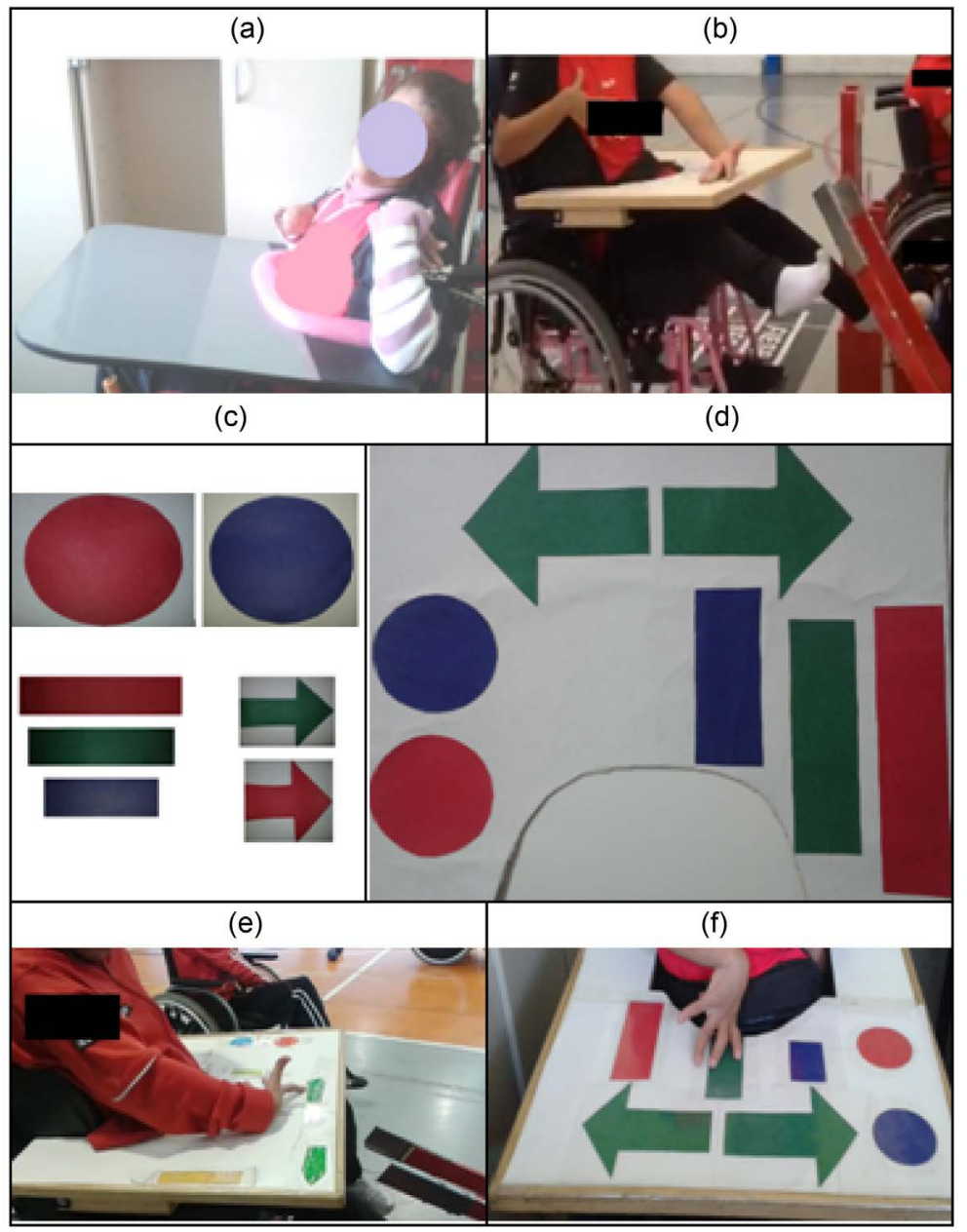

Figure 1. The sportive communication board (SCB) for CP-BC3-player of Boccia. (a)-(b) Adapted desk on wheelchair, commonly used for school or sportive purposes, respectively (c) and (d) The pieces of SCB and the final prototype, respectively and (e) and (f) SCB in use by CP-BC3-athlete (Personal collection). 
use of SCB may encourage these athletes to social interact, helping directly on their emotional well-being.

According to Krug and colleagues (Krug, 2002) recreation, competition and integration with other students, besides the opportunity to learn new movements, plays and games activities are important for CP people. These activities may offer full social interaction and encouragement for lowering their independence.

In Boccia, the selection of a sport assistant for attending $\mathrm{CP}-\mathrm{BC} 3$ player must consider a good relationship between them and the ability of understanding the athlete expressions, movements and gestures (Campeão \& Oliveira, 2006). The assistant should have good interaction with him/her, living with him/her after training, as well as participating in his/her daily activities. However, the substitution of sports assistant is a real possibility in official training and competitions which may generate problems in the interpretation of the athletes gestures and expressions by new sportive professionals.

\subsection{Questionnaires Analysis}

The questionnaires data analysis revealed that the interviewees knew the athlete, the boccia game and the communication performed in the $\mathrm{BC} 3$ classification. The analysis confirmed the clinical diagnosis of CP-BC3-player (sequelae of dystonic athetic spastic quadriplegia, with buccal-phonatory alterations), and the expression by using facial movements, upper limb and body language gestures. It was not possible to confirm schooling degree, but the athlete attended to school in rehabilitation centers, and is currently attending a specialized school. The analysis also revealed that the athlete recognizes her own name but has difficulty on identifying alphabet letters and numbers from 1 to 10 . She recognizes colors such as blue, red, green and white and geometric shapes such as circles and rectangles, as well as symbols such as direction arrows.

The questionnaire analysis also showed that both tutor and athlete have knowledge about alternative communication (AC) as they use a school board, already adapted and assembled for using with the family, at school, or socially. The legal tutor indicated positively the use of school board to the familiar and social communications. This type of AC is used in special education, with several possibilities of resources and methods for assembling adapted boards and offering to individuals with sequelae a more precisely communication (Manzini \& Deliberato, 2006).

According to the legal tutor, the $\mathrm{CP}-\mathrm{BC} 3$-athlete has played paralympic boccia for more than 1 year, participating in regional and state competitions during this period. The athlete always requested a sport assistant and her communication is performed through gestures in trainings and matches. It was pointed out the difficulties in this gestural communication in trainings and the need of the tutor to talk with the assistant, explaining the athlete commands. According to Boccia International Sports Federation (BIS-Fed) (BIS-FED, 2016), the game rules allow 
the athlete to be aided by a sport assistant, that should be with his back towards to the playing area all the time and eyes away from the match. The mediation of the tutor communication between the assistant and the athlete is not allowed by the official games rules, but only in training. In addition, the exchange of assistants during the athlete sporting life is likely to occur and the legal tutor is not always present to aid in the communication.

The sports assistants substitutions require the new assistant adaptation to the athlete gestural commands, demanding time and delaying the game process and athletes performance. Our SCB may be used by athletes with different assistants, facilitating the initial communication during training and games due to the standardized communication method that uses symbols and figures related to Boccia game environment and rules (Figure 1). According to our analysis, 75\% of the sportive assistants also including the legal tutor pointed the improvement in the communication process, through the understanding of the athlete commands by the assistant and the final positive result of ramp selection and positioning.

The sportive assistants pointed the use of facial and body gestures, including upper limbs, and upper body by the athletes. However, the majority (75\%) agreed and pointed out the difficulty of understanding and interpreted these movements and gestures to assist the athlete in the games without SCB. Only $25 \%$ reported having no difficulties on interacting with them. According to the sportive assistants, this high difficulty level in expressing the strategy ideas compromises the athlete's performance, revealing the high effort level requested by both professionals on communicating among them.

According to Palisiano and colleagues (Rosenbaum, Livingston, Palisano, Galuppi, \& Russell, 2007), GMFCS 5 cerebral paralyzed individuals exhibit difficulties in maintaining head and upper body posture and also in control of voluntary movements of upper and lower limbs. The difficulty of expressing themselves worsens their motor imbalances, which compromises the gestures and the attempt to communicate. The use of SBC where the signaling is arranged in front of the player on the school table affixed to the wheelchair make possible to point directly to the figure desired and thus show the right orientation of the ramp direction and the right strategy to play for winning (Figure 1(e) and Figure 1(f)).

Interestingly, the sports assistants understood the purpose of SCB, identified the symbols created and were unanimous in the recognition of the SCB effectiveness on improving the communication between them and the athlete (ITS, 2014). Carnevale and colleagues (Carnevale, Moraes, Berberian, \& Krüger, 2013) reported that graphic-visual stimuli with the purpose of interaction and communication generate possibilities of new social relations and better interaction for cerebral paralyzed patients with absence and/or difficulties on the oral speech.

According to the sports assistants, without using SBC, the full use of the six minutes (time allowed by the rule to the athlete elaborate the strategy and initiate the play) can be directly related to difficulties on understanding the athlete 
gestural movements. It was unanimous, after the SBC use, that less than the six minutes is required when using this alternative material to their communication.

\subsection{Video Analysis}

The video recording data analysis was performed by comparing four variables including: Mean distance from target ball (Figure 2(a)); Playing time (Figure 2(b)); Adversary balls out of bounds (Figure 2(c)); and Points taken (Figure $2(d))$. These variables were selected as they are important for winning Boccia game.

The data analysis pointed to the improvement of the variables and probably also to the communication between athlete and sports assistants by the SBC use. The improvement of the three variables (Distance of the target ball; Playing time; and Number of adversary balls far from Jack) reinforced this direct relationship, even in discrete values such as that observed for distance from target ball (2\%) (Table 1$)$.

The target ball is the white ball, also called "Jack", which the athletes must reach with their red or blue balls used during the game sets. The balls closest to Jack determine the number of points achieved and thus who win the match. The mean percentage of distance from the athlete's balls to Jack was analyzed without $(-\mathrm{SBC})$ and with sportive board $(+\mathrm{SBC})$ use. We also observed the waste of balls thrown out of the game area.

The ITS (ITS, 2014) indicates that students who have impairments related to
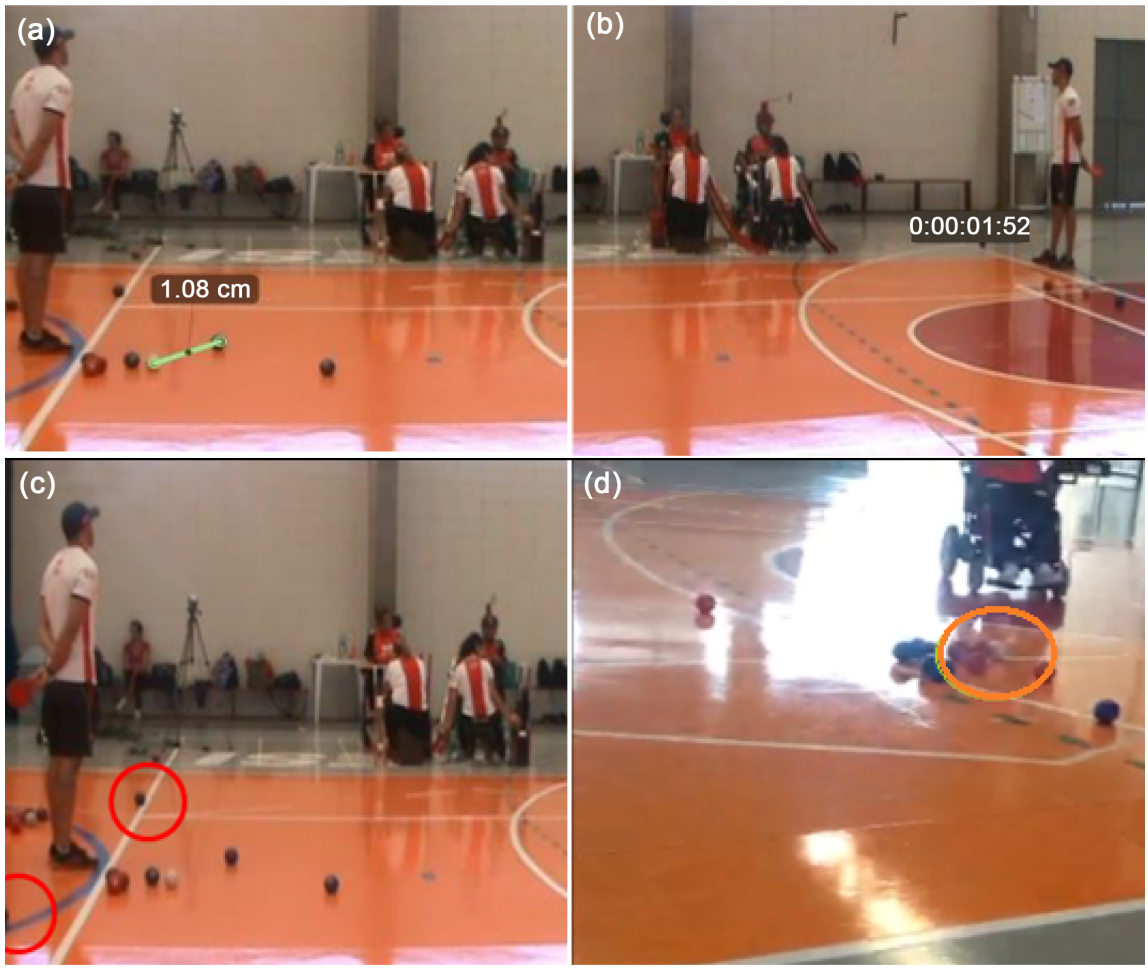

Figure 2. The four variables analyzed during the video-record: (a) Mean distance from target ball; (b) Playing time; (c) Adversary balls out of target (Jack); and (d) Points taken. 
Table 1. Comparison of the four variables (Distance from Target ball, Playing time, Adversary balls far from Jack, and Points taken) analyzed in the video recording of four sets without $(-\mathrm{SBC})$ and with $(+\mathrm{SBC})$ the Sportive Board $(\mathrm{n}=1$ each).

\begin{tabular}{|c|c|c|c|c|c|c|c|c|c|}
\hline \multicolumn{4}{|c|}{ Distance from target ball (Mean) } & \multicolumn{4}{|c|}{ Playing time (Mean) } & \multicolumn{2}{|c|}{ Adversary Ball far from target } \\
\hline \multicolumn{2}{|c|}{$-\mathrm{SBC}$} & \multicolumn{2}{|c|}{$+\mathrm{SBC}$} & \multicolumn{2}{|c|}{$-\mathrm{SBC}$} & \multicolumn{2}{|c|}{$+\mathrm{SBC}$} & $-\mathrm{SBC}$ & $+\mathrm{SBC}$ \\
\hline $1^{\circ}$ & 1.46 & $1^{\circ}$ & 0.59 & $1^{\circ}$ & 1.14 & $1^{\circ}$ & 0.58 & \multirow{2}{*}{0} & \multirow{2}{*}{0} \\
\hline $2^{\circ}$ & 0.14 & $2^{\circ}$ & 0.36 & $2^{\circ}$ & 0.41 & $2^{\circ}$ & 0.52 & & \\
\hline $3^{\circ}$ & 0.33 & $3^{\circ}$ & $-{ }^{*}$ & $3^{\circ}$ & 0.42 & $3^{\circ}$ & 0.40 & \multirow{2}{*}{0} & \multirow{2}{*}{4} \\
\hline $4^{\circ}$ & 0.22 & $4^{\circ}$ & $-{ }^{*}$ & $4^{\circ}$ & 0.41 & $4^{\circ}$ & 0.39 & & \\
\hline $5^{\circ}$ & 0.31 & $5^{\circ}$ & 1.02 & $5^{\circ}$ & 0.47 & $5^{\circ}$ & 0.49 & Total & 4 \\
\hline $6^{\circ}$ & $-*$ & $6^{\circ}$ & 0.10 & $6^{\circ}$ & 038 & $6^{\circ}$ & 0.57 & Difference (\%) & 33 \\
\hline $1^{\circ}$ & 0.44 & $1^{\circ}$ & 0.35 & $1^{\circ}$ & 0.45 & $1^{\circ}$ & 0.41 & \multicolumn{2}{|c|}{ Points taken } \\
\hline $2^{\circ}$ & 0.69 & $2^{\circ}$ & 0.60 & $2^{\circ}$ & 1.07 & $2^{\circ}$ & 0.52 & $-\mathrm{SBC}$ & $+\mathrm{SBC}$ \\
\hline $3^{\circ}$ & 0.66 & $3^{\circ}$ & 0.37 & $3^{\circ}$ & 0.54 & $3^{\circ}$ & 0.55 & 4 & 2 \\
\hline $4^{\circ}$ & 0.87 & $4^{\circ}$ & 1.85 & $4^{\circ}$ & 0.48 & $4^{\circ}$ & 0.37 & 2 & 4 \\
\hline $5^{\circ}$ & $-^{*}$ & $5^{\circ}$ & 0.20 & $5^{\circ}$ & 0.36 & $5^{\circ}$ & 0.40 & Total & 6 \\
\hline $6^{\circ}$ & 1.01 & $6^{\circ}$ & $-*$ & $6^{\circ}$ & 0.54 & $6^{\circ}$ & 0.34 & Difference (\%) & 0 \\
\hline Mean (\%) & 0.62 & & & Mean (\%) & 0.55 & & & & \\
\hline \multicolumn{2}{|c|}{ Difference (\%) } & \multicolumn{2}{|c|}{2} & \multicolumn{2}{|c|}{ Difference (\%) } & \multicolumn{2}{|c|}{18} & & \\
\hline
\end{tabular}

${ }^{*}$ Balls out of bounds.

motor coordination, cognitive and visual changes can benefit from the use of adapted pedagogical resources, providing independence and autonomy in the finalization of activities such as promoting facilitation in understanding and performing tasks. The sportive board adaptation on the wheelchair desk promotes ergonomic benefits to the athlete and consequently decreases the average time of play, providing better precision and strategy consistence and consequently ease understanding by the assistants (Manzini \& Deliberato, 2006).

Boccia can be played in categories $\mathrm{BC} 1, \mathrm{BC} 2, \mathrm{BC} 3$ and $\mathrm{BC} 4$ individually, or $\mathrm{BC} 3$ and $\mathrm{BC} 4$ in pairs. In individual, doubles and team games, the athletes will hold six, three, and two balls respectively, red or blue according to draw. Time limit to finish a move is then determined for each partial, expecting to be $6 \mathrm{mi}$ nutes for BC3 (BIS-FED, 2016). The analysis of time used of the athlete, without and with SBC was performed during the four sets.

According to our data, the average playing time of each ball in the first two sets, without the sportive board $(-\mathrm{SBC})$ was $18 \%$ higher compared to the last two, using the board (+SBC) (Table 1). Thus, these data suggested that SBC facilitated the understanding of intentions and play strategies of the player by the assistant. This corroborated the improvement in precision, since the athlete is constantly facing the playing area and watching the game, while the assistant stays backwards to the playing area as defined by the rules.

According to the rules, the game happens in a court with a specific area delimited by lines (Jerônimo, 2006). Court dimensions are $12.5 \mathrm{~cm}$ long and 6 meters wide with launch area divided into 6 boxes where the athletes stand with 
their wheelchairs, each box is 2.5 meters long and one meter wide and numbered 1 to 6 (BIS-FED, 2016). Boxes will be used according to the type of game (individual, pairs or team). In the playing area of the court there is a "V" line distant by 3 meters from the throwing line and 1.5 from its center point and the Jack must be threw by an athlete from inside the box and being required to exceed the "V" line. Balls that do not transpass "V" line are disregarded and balls that leave the court area will be considered off the field, causing the athlete to lose his/her turn and pass to the competitor. Thus, as strategies the athlete may try to reach Jack, and/or try to throw the opponent's ball far from Jack or hamper the opponent's play by inducing him to miss the target and throw his balls out of court. In this work, we analyzed if the BC3 athlete's balls were closest to the target and the strategies used as like balls near the opponent's and adversary loss of balls, with and without use of SBC.

There was an inverse relationship between the athlete's mean distance of the target ball (far from Jack) and the adversary's balls out of bound (who have crossed court lines) variables. Apparently, the higher number of errors, due to more difficulty of communication between athlete and assistants (-SCB) led to more dispersion of athlete's balls at a significant distance from the target ball leaving the court unobstructed, making it easier for the opponent's balls to approach the target ball. The use of SBC reverses this situation, becoming noticeable the significant decrease of space for the opponent balls in playing area, which end up out of boundary lines and increasing the efficacy of the strategy in statistics (Table 1).

This positive analysis corroborates the hypothesis that SBC favors the assistant understanding with positive results in the elaborated plays by the athletes. SCB may allow a better positioning of the ramp closest to the real athlete commands since it attends CP athletes with absence and/or difficulties of oral speech, due to its graphic-visual stimuli (Carnevale, Moraes, Berberian, \& Krüger, 2013).

Even with the SBC use, the Points taken did not varied, reveling the equilibrium between competitors (Table 1). It is important to note that $\mathrm{CP}-\mathrm{BC} 3$ athlete performed the test playing with athletes more capable than her as we could not found any BC3 to play with her. Thus, she played with a BC2 player (classification according to BIS-Fed regulation (BIS-FED, 2016)). The BC2 athlete does not require sport assistants as they throw the ball. This situation reinforced the importance of the improvement of the other three variables and the benefits involving the better communication between the $\mathrm{BC} 3$ athlete and her sportive assistant.

The analysis of the video of the games set without SBC revealed that the difficulty of speech articulation and verbal expression caused immense restlessness in the athlete, triggering exacerbation of typical athetosic movements with distorted characteristics of upper body and limbs. There is still possible to notice an apprehensive face in the attempt to execute gestures with movements to be understood and executed by assistants in order to execute the game move intended 
(not shown).

Despite the low motor coordination and the difficulty to maintain a symmetrical posture, when using SBC we observed the improvement of the athlete postural alignment and the upper limb gestures finalization. The location of SBC in the wheelchair promoted an inclination and support of upper body generating a better reach of the upper limbs in the direction to and the selection of the symbols.

The possibility of choosing the symbols during the game led to a clear tranquility and satisfaction face during the execution and finalization of the play.

\section{Conclusion}

The Paralympic Boccia is an inclusive sport that encourages the participation of athletes with serious motor impairments and/or wheelchair users in a very democratic way. Similar to other adapted modalities, it improves physical conditions and social relationships.

This work offered an alternative for communication between CP-BC3-players and sportive assistants by the use of a Boccia sportive board (SBC). According to our results, the athletes without oral speech who expresses through gestures, facial expressions, and other body language manifestations present significant difficulty on expressing their ideas and on being understood by other people. From the use of the SBC, the improvement of the understanding by the sport assistants of the athlete choices and commands resulted in directly benefits with more balls closer to the target, decrease in playing time and more balls of adversary outside of point area.

From this perspective, this new assistive technology tool may not only allow the communication between athletes and their sport assistants in Boccia, but also can be adapted to other sports.

\section{Conflicts of Interest}

The authors declare no conflicts of interest regarding the publication of this paper.

\section{References}

Alves, N. P. F., \& Cruz, M. F. S. (2014). O Efeito da Prática de Bocha Adaptada nos Prtadores de Seqüela de Paralisia Cerebral. Proceedings of the Simpósio Internacional de Ciências Integradas da UNAERP Campus Guarujá, Guarujá, SP.

Alvis, K., \& Mejía, M. (2013). Boccia: Factor de integración social y su significado en mujeres y hombres adscritos a la liga de parálisis cerebral de Bogotá. Revista de la Facultad de Medicina, 61, 70-80.

Ayres, M., Ayres Júnior, M., Ayres, D. L., \& Santos, A. D. A. (2007). Aplicações estatísticas nas áreas das ciências bio-médicas (p. 364). Belém: Instituto Mamirauá.

Bardin, L. (2006). Análise de conteúdo. (L. de A. Rego \& A. Pinheiro, Trads.). Lisboa: Edição 70.

BIS-FED (2016). Boccia Internacional Sports Federation. About Boccia Classification. http://www.bisfed.com/about-boccia/classification 
Campeão, M. D. S., \& Oliveira, R. D. (2006). Bocha paraolímpica: manual de orientação para professores de educação física. Brasília: Comitê Paraolímpico Brasileiro, 1, 42.

Cardoso, V. D. (2011). A reabilitação de pessoas com deficiência através do desporto adaptado. Revista Brasileira de Ciências do Esporte, 33, 529-539.

https://doi.org/10.1590/S0101-32892011000200017

Carnevale, L. B., Moraes, P. D. D., Berberian, A. P., \& Krüger, S. (2013). Comunicação Alternativa no contexto educacional: conhecimento de professores. Revista Brasileira de Educação Especial, 19, 243-256. https://doi.org/10.1590/S1413-65382013000200008

Castellano, G. B., \& Freire, R. M. A. D. C. (2014). O diagnóstico fonoaudiológico na paralisia cerebral: o sujeito entre a fala e a escuta. Ágora: Estudos em Teoria Psicanalítica, 17, 117-134. https://doi.org/10.1590/S1516-14982014000100008

da Fonseca, J. O., Cordani, L. K., \& de Oliveira, M. C. (2005). Aplicação do inventário de avaliação pediátrica de incapacidade (PEDI) com crianças portadoras de paralisia cerebral tetraparesia espástica. Revista de Terapia Ocupacional da Universidade de São Paulo, 16, 67-74. https://doi.org/10.11606/issn.2238-6149.v16i2p67-74

de Oliveira, A. I. A., Golin, M. O., \& Cunha, M. C. B. (2010). Aplicabilidade do Sistema de Classificação da Função Motora Grossa (GMFCS) na paralisia cerebral-revisão da literatura. Arquivos Brasileiros de Ciências da Saúde, 35, 220-224.

https://doi.org/10.7322/abcs.v35i3.85

Fong, D. T. P., Yam, K. Y., Chu, V. W. S., Cheung, R. T. H., \& Chan, K. M. (2012). Upper Limb Muscle Fatigue during Prolonged Boccia Games with Underarm Throwing Technique. Sports Biomechanics, 11, 441-451. https://doi.org/10.1080/14763141.2012.699977

Huang, P. C., Pan, P. J., Ou, Y. C., Yu, Y. C., \& Tsai, Y. S. (2014). Motion Analysis of Throwing Boccia Balls in Children with Cerebral Palsy. Research in Developmental Disabilities, 35, 393-399. https://doi.org/10.1016/j.ridd.2013.11.017

ITS (2014). Instituto de Tecnologia Social Cartilha de Tecnologia Assistiva nas escolas: Recursos básicos de acessibilidade sócio-digital para pessoa com deficência. http://www.itsbrasil.org.br/sites/itsbrasil.w20.com.br/files/Digite_o_texto/Cartilha_Tecnolo gia_Assistiva_nas_escolas_-_Recursos_basicos_de_acessibilidade_socio-digital_para_p essoal_com_deficiencia.pdf

Jerônimo, J. P. (2006). Esporte como Elemento Facilitador da Inclusão de Pessoas com Paralisia Cerebral Severa: contribuição para a formação de professores de Educação Física. Master's Dissertation, Uberaba: Universidade de Uberaba.

Kinovea Software Version 0.8.15 for Windows (2016). https://www.kinovea.org

Krug, H. N. (2002). A inclusão de pessoas portadoras de necessidades educativas especiais na educação física escolar. Revista Educação Especial, 15-23.

Leite, J. M. R. S., \& Prado, G. D. (2004). Paralisia cerebral: Aspectos fisioterapêuticos e clínicos. Revista Neurociências, 12, 41-45. https://doi.org/10.4181/RNC.2004.12.41

Lianza, S. (2007). Medicina de Reabilitação-Associação Brasileira de Medicina Física e Reabilitação. Rio de Janeiro: Guanabara Koogan.

Manzini, E., \& Deliberato, D. (2006). Portal de ajudas técnicas para educação: Equipamento e material pedagógico especial para educação, capacitação e recreação da pessoa com deficiência física: Recursos para comunicação alternativa (2nd ed., 52 p.). Brasília: MEC, SEESP. http://portal.mec.gov.br/seesp/arquivos/pdf/ajudas_tec.pdf

Morriss, L., \& Wittmannová, J. (2011). The Effect of Blocked versus Random Training Schedules on Boccia Skills Performance in Experienced Athletes with Cerebral Palsy. European Journal of Adapted Physical Activity, 3, 17-28. 
Mozzato, A. R., \& Grzybovski, D. (2011). Análise de conteúdo como técnica de análise de dados qualitativos no campo da administração: Potencial e desafios. Revista de Administração Contemporânea, 15, 731-747. https://doi.org/10.1590/S1415-65552011000400010

Pelosi, M. B. (2008). Inclusão e tecnologia assistiva. Thesis, Rio de Janeiro: Doutorado em Educação-Programa de Pós-Graduação em Educação, Universidade do Estado do Rio de Janeiro.

Rosenbaum, P. L., Livingston, M. H., Palisano, R. J., Galuppi, B. E., \& Russell, D. J. (2007). Quality of Life and Health-Related Quality of Life of Adolescents with Cerebral Palsy. Developmental Medicine \& Child Neurology, 49, 516-521. https://doi.org/10.1111/j.1469-8749.2007.00516.x

Rotta, N. T. (2002). Paralisia cerebral: Novas perspectivas terapêuticas. Jornal de Pediatria, 78, S48-S54. https://doi.org/10.1590/S0021-75572002000700008

Shepherd, R. B. (1995). Fisioterapia em Pediatria (3rd ed., pp. 338-343). São Paulo: Editora Santos.

Silva, R. L. M. D., Silva, S. S. D. C., Pontes, F. A. R., Oliveira, A. I. A. D., \& Deliberato, D. (2013). Efeitos da comunicação alternativa na interação professor-aluno com paralisia cerebral não-falante. Revista Brasileira de Educação Especial, 19, 25-42. https://doi.org/10.1590/S1413-65382013000100003

Tsai, Y. S., Yu, Y. C., Huang, P. C., \& Cheng, H. Y. K. (2014). Seat Surface Inclination May Affect Postural Stability during Boccia Ball Throwing in Children with Cerebral Palsy. Research in Developmental Disabilities, 35, 3568-3573. https://doi.org/10.1016/j.ridd.2014.08.033

Zonta, M. B., Ramalho Júnior, A., \& Santos, L. H. C. (2011). Avaliação funcional na paralisia cerebral. Acta Pediátrica Portuguesa, 42, 27-32. 


\section{Appendix}

\section{Questionnaire Destined to Class Three Boccia Athlete's Sports Assistants}

This is a questionnaire elaborated to mater degree research entitled "Utilization of a Communication Board for Athletes with Chronic Non-Progressive Encephalopathies Spastic Quadriplegics with Dystonic Athetosis, on Paralympic Boccia games" and executed by Ana Paula de Araújo Alves relative to the application of a communication board for athletes with chronic non-progressive encephalopathies spastic quadriplegics with dystonic athetosis on Paralympic boccia games, in Boccia Class Three. The questionnaire will be applied to Boccia class three athlete's sports assistants. The participation of the interviewees is voluntary, with no onus or bonuses involved, and may at any time desist from participating. The information obtained through this research will be confidential and the confidentiality of the participation of the interviewees will be ensured by disseminating the results obtained in the questionnaires in scientific texts and events.

First You Will Answer about Yourself:

Age: Sex:

Schooling:

Time as athlete's Sports Assistants:

( ) Less than 6 months

( ) Between 6 months - 1 year

( ) Between 1 to 3 years

( ) Over 3 years

Aware of the School Alternative Communication Board?

( ) Yes

( ) No

( ) Don't know

Are there communication difficulties between athletes and sports assistants?

( ) Yes, because

( ) No, because

In your opinion, the communication between athletes and sports assistants, through gestures, is always effective for in game strategies elaborations?

( ) Yes, because

( ) No, because

In your opinion, has your communication with the athlete been effective for in game strategies elaborations?

( ) Yes, because

( ) No, because

( ) Not sure because

\section{Now You Will Answer Questions Regarding the Athlete:}

Communication between you and the athlete is performed through facial gestures? 
( ) Yes

( ) No

( ) Don't know

Communication between you and the athlete is performed through bodily gestures from the upper limbs only?

( ) Yes

( ) No

( ) Don't know

Communication between you and the athlete is performed through bodily gestures of the thorax and upper limbs?

( ) Yes

( ) No

( ) Don't know

Class three of the Paralympic Boccia game features a 6-minute play time, you and the athlete:

( ) Take less than the time limit for in game strategies elaborations (e.g. 4 $\min )$ ?

( ) Take the whole time limit for in game strategies elaborations (full 6min)?

( ) Take more than the time limit for in game strategies elaborations?

There are any communication difficulties between you and the athlete?

( ) Yes, which ones?

( ) No

In the need of changing the sport assistant in a competition, this could disturb:

( ) Communications

( ) In game strategies elaborations

( ) Other(s)

( ) No disturbance

Questionnaire Answer after Using the Sportive Communication Board (Sports Assistants):

Did you understand the proposal of the alternative communication board for the boccia game?

( ) Yes

( ) No

Did you understand the symbols of the alternative communication board for the boccia game?

( ) Yes

( ) No

The symbols used in the alternative communication board are effective for communication between athlete and sports assistants?

( ) Yes, because

( ) No, because

The symbols used on the alternative communication board are comprehensible to the athlete? 
( ) Yes, because

( ) No, because

Do you think the athlete understood the proposal of the alternative communication board for boccia game?

( ) Yes, because

( ) No, because

\section{Questionnaire Destined to Class Three Boccia Athlete's Legal Tutor}

This is a questionnaire elaborated to mater degree research entitled "Utilization of a Communication Board for Athletes with Chronic Non-Progressive Encephalopathies Spastic Quadriplegics with Dystonic Athetosis, on Paralympic Boccia games" and executed by Ana Paula de Araújo Alves relative to the application of a communication board for athletes with chronic non-progressive encephalopathies spastic quadriplegics with dystonic athetosis on Paralympic boccia games, in Boccia Class Three. The questionnaire will be applied to Boccia class three athlete's legal tutor, since those athletes presents quadriplegia motor sequelae impairing their motor coordination for writing, besides buccal-phonatory alteration's aphasia, which hinder the directly answer to questionnaire The information obtained through this research will be confidential and the confidentiality of the participation of the interviewees will be ensured by disseminating the results obtained in the questionnaires in scientific texts and events.

First You Will Answer about Yourself:

Age:

Sex:

Schooling:

Relationship with the athlete:

( ) Parents

( ) Grandparents

( ) Siblings

( ) Caregiver

( ) Husband/Wife

( ) Other

Aware of the School Alternative Communication Board?

( ) Yes

( ) No

( ) Don't know

Now You Will Answer Questions On Behalf Of The Athlete:

Age:

Sex:

Schooling:

The Athlete Presents a Clinical Diagnosis of Cerebral Palsy?

( ) Yes

( ) No

( ) Don't know 
The Athlete Presents Cerebral Palsy Dystonic Athetic Spastic Quadriplegia Motor Sequelae?

( ) Yes

( ) No

( ) Don't know

The Athlete Presents Buccal-Phonatory Alterations Hindering The Speech?

( ) Yes

( ) No

( ) Don't know

The Athlete Understand and Identify Alphabet Letters?

( ) Yes

( ) No

( ) Don't know

The Athlete Understand and Identify Numbers from 1 to 10 ?

( ) Yes

( ) No

( ) Don't know

The Athlete Identify the Colors: Blue, Red, Green and White (Colors Present in the Boccia Game Universe)?

( ) Yes

( ) No

( ) Don't know

The Athlete Have Knowledge Of The School Communication Board?

( ) Yes

( ) No

( ) Don't know

Has The Athlete Been To School?

( ) Yes, But Not Anymore

( ) Yes, and It Is in Grade

( ) No, Never. But Have Homeschooling

( ) No, Never and Don't Have Homeschooling

The Athlete Makes Use of The School Communication Board in School?

( ) Yes

( ) No

( ) Don't know

The Athlete Makes Use of the Alternative Communication Board with the Family?

( ) Yes

( ) No

( ) Don't know

The Athlete Makes Use of the Alternative Communication Board in Social Context?

( ) Yes 
( ) No

( ) Don't know

The Athlete Needs a Sport Assistant during Trainings and in Boccia Games?

( ) Yes

( ) No

( ) Don't know

The Athlete Practice Boccia:

( ) Less Than an Year

( ) More Than an Year

The Athlete Already Have Participated in Regional Competitions?

( ) Yes and Ranked in Place

( ) No

( ) Don't Know

The Athlete Already Have Participated in State Competitions?

( ) Yes and Ranked in Place

( ) No

( ) Don't Know

The Athlete Already Have Participated in National Competitions?

( ) Yes and Ranked in Place

( ) No

( ) Don't Know

The Athlete Already Have Participated in International Competitions?

( ) Yes and Ranked in Place

( ) No

( ) Don't Know 